Atmos. Chem. Phys., 10, 6295-6309, 2010

www.atmos-chem-phys.net/10/6295/2010/

doi:10.5194/acp-10-6295-2010

(C) Author(s) 2010. CC Attribution 3.0 License.

\title{
Ozone predictabilities due to meteorological uncertainties in the Mexico City basin using ensemble forecasts
}

\author{
N. Bei ${ }^{1}$, W. Lei ${ }^{1}$, M. Zavala ${ }^{1}$, and L. T. Molina ${ }^{1,2}$ \\ ${ }^{1}$ Molina Center for Energy and the Environment, La Jolla, California, USA \\ ${ }^{2}$ Department of Earth, Atmospheric and Planetary Sciences, Massachusetts Institute of Technology, Cambridge, \\ Massachusetts, USA
}

Received: 8 January 2010 - Published in Atmos. Chem. Phys. Discuss.: 5 February 2010

Revised: 11 June 2010 - Accepted: 28 June 2010 - Published: 13 July 2010

\begin{abstract}
The purpose of the present study is to investigate the sensitivity of ozone $\left(\mathrm{O}_{3}\right)$ predictions in the Mexico City Metropolitan Area (MCMA) to meteorological initial uncertainties and planetary boundary layer (PBL) parameterization schemes using state-of-the-art meteorological and photochemical prediction models through ensemble forecasts. The simulated periods (3, 9, 15 and 29 March 2006) represent four typical meteorological episodes ("SouthVenting", "O ${ }_{3}$-North", "O $\mathrm{O}_{3}$-South" and "Convection-North", respectively) in the Mexico City basin during the MCMA2006/MILAGRO campaign. Our results demonstrate that the uncertainties in meteorological initial conditions have significant impacts on $\mathrm{O}_{3}$ predictions, including peak time $\mathrm{O}_{3}$ concentrations $\left(\left[\mathrm{O}_{3}\right]\right)$, horizontal and vertical $\mathrm{O}_{3}$ distributions, and temporal variations. The ensemble spread of the simulated peak $\left[\mathrm{O}_{3}\right]$ averaged over the city's ambient monitoring sites can reach up to $10 \mathrm{ppb}$. The increasing uncertainties in meteorological fields during peak $\mathrm{O}_{3}$ period contribute to the largest unpredictability in $\mathrm{O}_{3}$ simulations, while the impacts of wind speeds and PBL height on $\left[\mathrm{O}_{3}\right]$ are more straightforward and important. The magnitude of the ensemble spreads varies with different PBL schemes and meteorological episodes. The uncertainties in $\mathrm{O}_{3}$ predictions caused by PBL schemes mainly come from their ability to represent the mixing layer height; but overall, these uncertainties are smaller than those from the uncertainties in meteorological initial conditions.
\end{abstract}

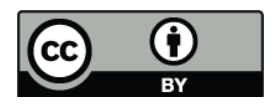

Correspondence to: N. Bei (bnf@mce2.org)

\section{Introduction}

The predictability of the weather is inherently limited because of the chaotic nature of the atmosphere (Lorenz, 1969). The limited deterministic predictability in numerical weather prediction (NWP) has been extensively studied (see e.g., Leith and Kraichnan, 1972; Anthes et al. 1985; Errico and Baumhefner, 1987; Vukicevic and Errico, 1990; Zhang et al., 2002, 2003; Tribbia and Baumhefner, 2004; Zhang et al., 2006; Bei and Zhang, 2007). It has been found that the error grows with the background dynamics and the error growth is strongly nonlinear. Smaller amplitude initial errors, which are far smaller than those of current observational networks, may grow rapidly and quickly saturate at smaller scales. These errors successively grow upscale, leading to significant forecast uncertainties at increasingly larger scales. Besides, moist convection is found to be the key to the rapid error growth that leads to limited predictability at the mesoscales. Ensemble techniques are commonly used to improve the forecast ability of meteorological models (e.g., Kalnay, 2003) and have been successfully applied to dispersion forecasts of radionuclides and inert tracers (Galmarini et al., 2004, and references therein).

An ensemble forecast system is composed of multiple individual numerical forecasts (members) generated from a set of different initial conditions and/or different numerical configurations (Leith, 1974). In addition, probabilistic forecasts, which have been presented elsewhere (e.g., Buizza et al., 1993; Toth and Kalnay, 1993; Mullen and Buizza, 2002), can also be obtained from the relative frequencies of events represented in the ensemble.

Published by Copernicus Publications on behalf of the European Geosciences Union. 
Ensemble prediction systems have been widely used operationally in meteorological centers around the world, such as the National Centers for Environmental Prediction (NCEP) (Toth and Kalnay, 1993), the European Center for MediumRange Weather Forecasts (ECMWF) (Buizza, 1997), and the Meteorological Service of Canada (MSC) (Houtekamer and Lefaivre, 1997). The ensemble mean was found to be more accurate than an individual model realization, when verified for numerous cases. NWP ensembles could be implemented by using different model initial conditions (Toth and Kalnay, 1993, 1997; Molteni et al., 1996), different parameterizations within a single model (Stensrud et al., 1998), different numerical schemes (Thomas et al., 2002), and different models (Hou et al., 2001; Wandishin et al., 2001). This allows the ensemble to consider different sources of uncertainties.

The ensemble technique can yield similar benefits to realtime air quality prediction because there are similar model complexities and constraints. For example, a probabilistic approach to air quality forecasting has been recommended by the US Weather Research Program and its Prospectus Development Team on Air Quality Forecasting (Dabberdt et al., 2003) because of the chaotic nature of the atmosphere and chemistry nonlinearity. Delle Monache and Stull (2003) have discussed the benefits of the ensemble approach through the use of different Chemical Transport Models (CTMs) and the associated photochemical reactions. Galmarini et al. (2004b) have tested a multimodel ensemble dispersion system by considering several operational long-range transport and dispersion models. They found that the median member of the forecast ensemble exhibited the best forecast skill. McKeen et al. (2005) have presented results for a multimodel (i.e., seven CTMs) Ozone Ensemble Forecast System (OEFS), statistically evaluated for 53 days against 340 monitoring stations over eastern US and southern Canada. Their results showed that the ensemble mean is the preferred forecast when compared to any individual model. Mallet and Sportisse (2006) have conducted ensemble photochemical simulations using different physical parameterizations. Delle Monache et al. (2006a) have tested a new OEFS to improve the accuracy of real-time photochemical air quality modeling using different meteorological and photochemical models together with different emission scenarios. In all cases, the ensemble means perform better than most models individually.

Recent studies have also demonstrated that air quality forecasts can be further improved through weighted ensemble means (e.g., Delle Monache et al., 2006b; Pagowski et al., 2005). Using both meteorological and photochemical ensemble forecasts, Zhang et al. (2007a) have showed that there are large uncertainties in the $\mathrm{O}_{3}$ prediction in Houston and surrounding areas due to initial meteorological uncertainties. This has further demonstrated the importance of accurate representation of meteorological conditions and the need for probabilistic evaluation and forecasting for air pollution in urban areas. Mao et al. (2006) have conducted $\mathrm{O}_{3}$ prediction sensitivities due to PBL schemes through deter- ministic forecasts. Their results show that the option of PBL schemes in MM5 does not appreciably affect the CMAQ performance when the evaluations are averaged throughout the entire modeling domain. However, on an urban scale the differences in $\mathrm{O}_{3}$ prediction across different PBL schemes are considerable.

The Mexico City Metropolitan Area (MCMA) is situated inside a basin at an elevation of $2240 \mathrm{~m}$ above sea level (m.s.l) at $19.4 \mathrm{~m}^{\circ} \mathrm{N}$ latitude and is surrounded on three sides by mountains averaging over $3000 \mathrm{~m}$ (m.s.l) (see Fig. 1b). The main opening of the basin is towards the Mexico Plateau to the north. To the southeast there is a gap in the mountains, referred to as the Chalco passage, which leads to significant gap winds. The combination of weak winds and numerous emission sources results in high levels of air pollutions (Molina and Molina, 2002). Because of its complex topography, the meteorology of the MCMA depends on the interplay of the basin with the Mexican Plateau and the lower coastal areas (along the eastern Pacific Ocean and the Gulf of Mexico). Both regional and synoptic-scale meteorological conditions are important for understanding flows and dispersions within the Mexico City basin (Bossert, 1997). The complex wind circulation in the Mexico City basin and its role in the formation of surface air pollution distributions in the basin have been analyzed extensively in previous studies (e.g., Wellens et al., 1994, 1995; Streit and Guzman, 1996; Jauregui, 1997; Fast and Zhong, 1998; Doran and Zhong, 2000; Jazcilevich et al., 2003) and more recently during the MCMA-2003 Campaign (de Foy et al., 2005, 2006a, b). As a major field study investigating the atmospheric chemistry of the MCMA, the MCMA-2003 campaign has revealed important new insights into the meteorology, primary pollutant emissions, ambient secondary pollutant precursor concentrations, photochemical oxidant production, and secondary aerosol particle formation in the North America's most populated megacity (Molina et al., 2007). Bei et al. (2008) have investigated the effects of using a three-dimensional variational data assimilation (3DVAR) system in meteorological modeling to improve $\left[\mathrm{O}_{3}\right]$ simulations in the Mexico City basin during MCMA-2003 campaign, and demonstrated the importance of applying data assimilation in meteorological simulations of air quality in the Mexico City basin. Still, there are discrepancies between $\mathrm{O}_{3}$ predictions and observations due to the uncertainties in meteorological field simulations for some of the days (Lei et al., 2007, 2008).

To better understand the evolution of trace gases and particulates originating from anthropogenic emissions in the MCMA and their impact on regional air quality and climate, a field campaign called the Megacities Initiative: Local And Global Research Observations (MILAGRO) has collected a wide range of meteorological, gaseous and particulate measurements during March 2006 (Molina et al., 2010). Fast et al. (2007) described the large-scale meteorological conditions that affected atmospheric chemistry over Mexico during March 2006 and defined three regimes that 


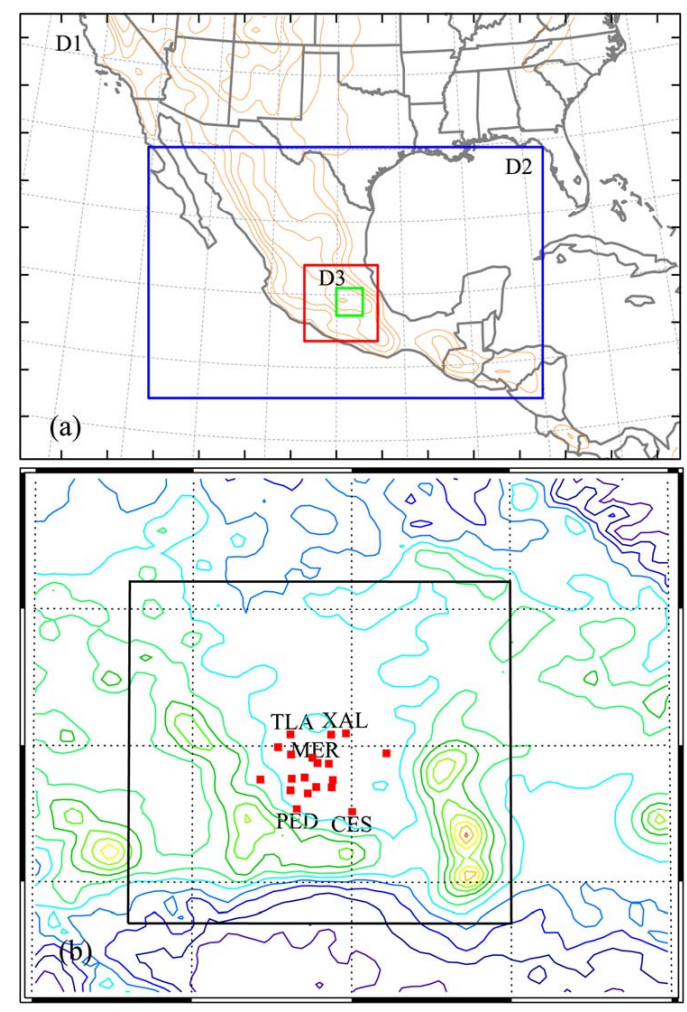

Fig. 1. (a) WRF domains (black, blue, red box) and (b) CAMx domain (green box in Fig. 1a, Square signs are RAMA stations for ozone measurements). Inner box indicates the domain shown in Figs. 6 and 8. Contours in both panels represent terrain height.

characterized the overall meteorological conditions: the first regime prior to 14 March, the second regime between 14 and 23 March, and the third regime after 23 March. de Foy et al. (2008) used cluster analysis to identify the dominant wind patterns in the Mexico City basin both during the campaign and within the past 10 years of operational data from the warm dry season. The basin-scale circulation was categorized by the following six episodes: " $\mathrm{O}_{3}$-South", "O ${ }_{3}$-North", "Cold Surge", "South-Venting", "ConvectionSouth", and "Convection-North".

We have further developed and improved the meteorological simulations during MILAGRO 2006 (one month long) to better understand the air pollution in the MCMA by using Four Dimensional Data Assimilation system (WRFFDDA). The incorporated observational data include conventional observations and special observations available during the MILAGRO field campaign (such as radar wind profilers, tethered balloon measurements, controlled meteorological balloon observations, aircraft observations, mobile surface observations, and extra soundings inside the Mexico City basin). This improved meteorological data set has been applied to a study on the $\mathrm{O}_{3}$ formation and its sensitivity to precursor emissions under five different meteorological con- ditions in the MCMA during the MCMA-2006/MILAGRO field campaign using gridded photochemical model CAMx (Song et al., 2010). Tie et al. (2009) have also studied the $\mathrm{O}_{3}$ formation in Mexico City and the surrounding areas during the MIRAGE-Mex/MILAGRO using a regional chemical/transport model (WRF-CHEM). The purpose of this study is to investigate the uncertainties of $\mathrm{O}_{3}$ predictions in the Mexico City basin due to meteorological uncertainties, which arise from initial conditions and PBL parameterization schemes. The impacts of meteorological uncertainties on $\mathrm{O}_{3}$ predictability have been investigated through ensemble forecasts using state-of-the-art meteorological and photochemical prediction models for four selected days $(3,9$, 15, and 29 March 2006) that represent four typical meteorological episodes ("South-Venting", "O $\mathrm{O}_{3}$-North", "O ${ }_{3}$-South", and "Convection-North") in the Mexico City basin during MILAGRO/MCMA-2006 (de Foy et al., 2008). The models and experimental designs are presented in Sect. 2. The synoptic situations of the selected days are overviewed in Sect. 3. The control ensemble forecasts are introduced in Sect. 4. The ensemble forecasts with different PBL schemes are presented in Sect. 5. The ensemble simulations on other episodes are discussed in Sect. 6. The conclusions are summarized in Sect. 7.

\section{Forecast models, ensemble generation, and experimental design}

The Advanced Research WRF (ARW) (WRF v2.2.1; Skamarock et al., 2005) is used in meteorological deterministic and ensemble forecasts. The model simulations adopt three one-way nested grids with horizontal resolutions of 36,12 , and $3 \mathrm{~km}$ and 35 sigma levels in the vertical direction (Fig. 1a). The grid cells used for the three domains are $145 \times 95,259 \times 160$, and $193 \times 193$, respectively. The WRF model is initialized at 00:00 UTC and integrated for $30 \mathrm{~h}$. The NCEP Global Forecast System (GFS) final (FNL) global gridded analysis is used to produce the initial and boundary conditions for the reference deterministic forecast. The physical process parameterization schemes used in the reference deterministic forecasts include the modified Kain-Fritsch cumulus scheme (KF-Eta) (Kain and Fritsch, 1993), the WRF Single Moment (WSM) three-class microphysics (Hong et al., 2004), and Mellor-Yamada-Janjic (MYJ) TKE scheme (Janjic, 2002) for PBL processes.

An initial ensemble is generated with the WRF-3DVAR (Barker et al., 2004) using Background Error Statistics (BES) option cv5. A set of random control vectors with a normal distribution was generated. A control increment vector is then transformed back to model space via an empirical orthogonal functions (EOF) transform, a recursive filter, and physical transformation via balance equation. The perturbed variables include the horizontal wind components, potential temperature, perturbation pressure, and mixing ratio of 

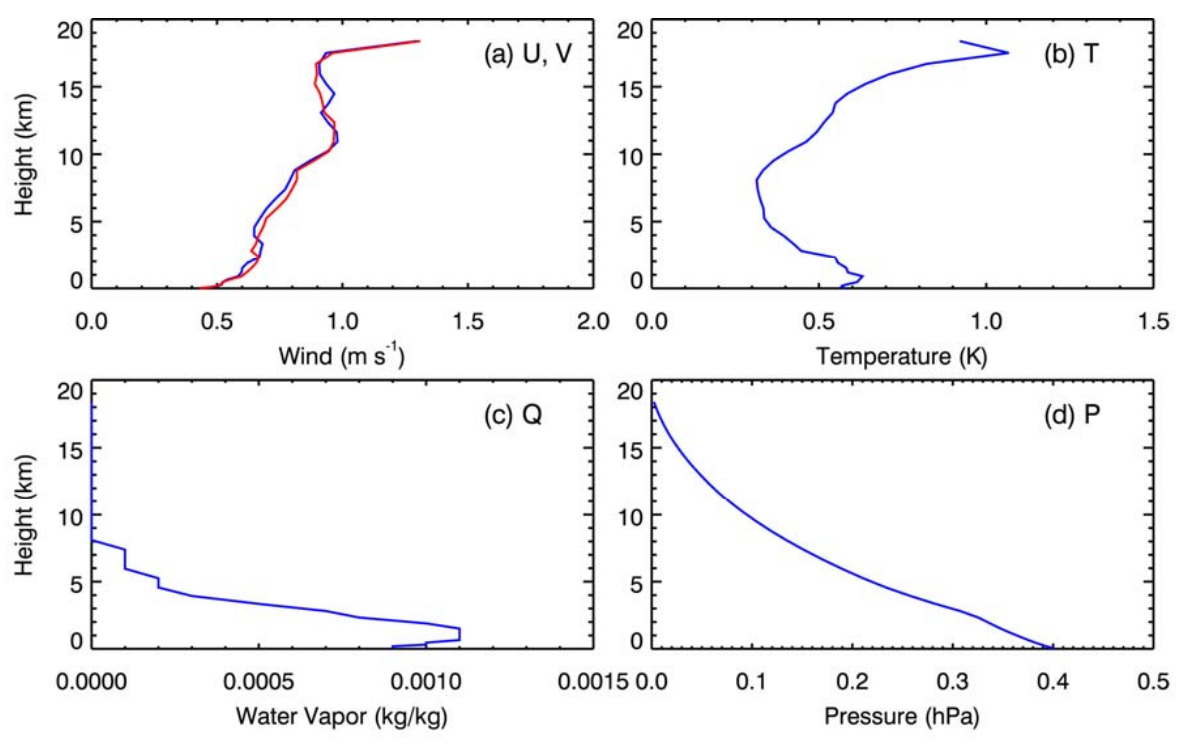

Fig. 2. Vertical distribution of the initial ensemble spread for (a) horizontal winds $(u, v, \mathrm{~m} / \mathrm{s})$, (b) temperature $(T, \mathrm{~K}),(\mathbf{c})$ pressure $(p, \mathrm{hPa})$, and (d) water vapor mixing ratio $(q, \mathrm{~g} / \mathrm{kg})$ over domain 1 .

water vapor, whose error statistics are defined by the domainspecific climatological background error covariance that are derived from the one-month simulations in the same domain using the NMC method (Parrish and Derber, 1992). Other prognostic variables such as vertical velocity $(w)$ and mixing ratios of cloud water $\left(q_{\mathrm{c}}\right)$, rain water $\left(q_{\mathrm{r}}\right)$, snow $\left(q_{\mathrm{s}}\right)$ and graupel $\left(q_{\mathrm{g}}\right)$ are not perturbed.

Figure 2 shows the vertical distribution of the initial ensemble spread (the average difference between the individual ensemble forecasts of a quantity and the ensemble mean forecast of the quantity), which is $0.4-1.3 \mathrm{~m} / \mathrm{s}$ for horizontal winds $(u, v), 0.3-1.0 \mathrm{~K}$ for temperature $(T), 0-0.4 \mathrm{hPa}$ for pressure $(p)$, and $0-1.2 \mathrm{~g} / \mathrm{kg}$ for the water vapor mixing ratio $(q)$. The 3DVAR perturbations are added to NCEP (GFS-FNL) data to form an initial ensemble, which is then integrated for $30 \mathrm{~h}$ to produce the ensemble forecasts. The perturbations generated through this method are random and balanced noises, and their magnitudes are also small compared to the typical sounding observational and analysis errors (Nielsen-Gammon et al., 2007). Similar methods to generate the initial ensemble are also employed by Meng and Zhang (2008) and Barker (2005). The boundary conditions (interpolated from the GFS analysis at different times) are perturbed in the same manner as the initial ensemble.

The 3-km meteorological ensemble simulations are then used to drive a 20-member photochemical ensemble forecast using the Eulerian photochemical grid model CAMx v4.40 (Environ, 2006). The CAMx model domain $(70 \times 70$ grids, Fig. 1b) is much smaller than the WRF domain 3 because of available computing resources and emissions data. The model set-up and the input data used for CAMx in this study are the same as those described in Song et al. (2010) except the meteorological fields. The emission input is constructed based on the official MCMA emissions inventory for the year 2006 (SMA-DF, 2008) and is adjusted based on comprehensive field measurements of $\mathrm{O}_{3}$ precursors, as described in Song et al. (2010). For all the experiments, the initial and boundary conditions for chemical fields are the same, since we only focus on the effects due to changes in the meteorological fields.

Both meteorological and photochemical ensemble forecasts are conducted on four selected days $(3,9,15$, and 29 March 2006). We choose 3 March as a control ensemble run (CTRL), and most analyses are performed only on this day. The physical process parameterization schemes used in the CTRL run are the same as those used in the reference deterministic forecast.

Uncertainties in air quality modeling arise when different physical parameterization schemes are used in meteorological models (see e.g., Alapaty et al., 1994; Pielke and Uliasz, 1998). One of the most important meteorological parameters that affect the uncertainties in models predictions is the planetary boundary layer (PBL). We have verified the impact of PBL parameterization schemes on the $\mathrm{O}_{3}$ simulation of 3 March 2006 by conducting ensemble forecasts using other two different PBL schemes, which include the Yonsei University (YSU) scheme (Noh et al., 2003) and the MediumRange Forecast (MRF) model (Hong and Pan, 1996).

\section{Overview of the synoptic conditions}

The four days selected in this paper represent four different meteorological episodes types in Mexico City. 3 March 

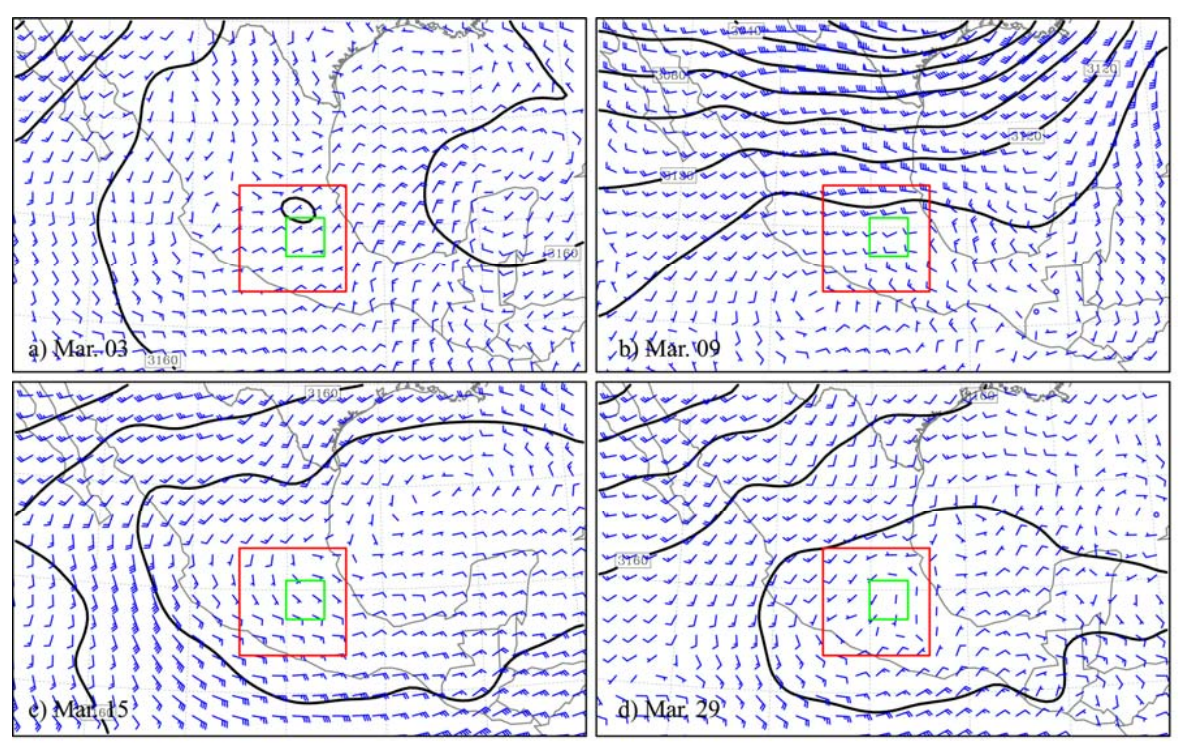

Fig. 3. The $700 \mathrm{hPa}$ geopotential heights and winds at 12:00 CDT from GFS-FNL reanalysis data for (a) 3 March, (b) 9 March, (c) 15 March, and (d) 29 March, 2006. Red box indicates domain3 used in WRF. Green box indicates the CAMx domain.

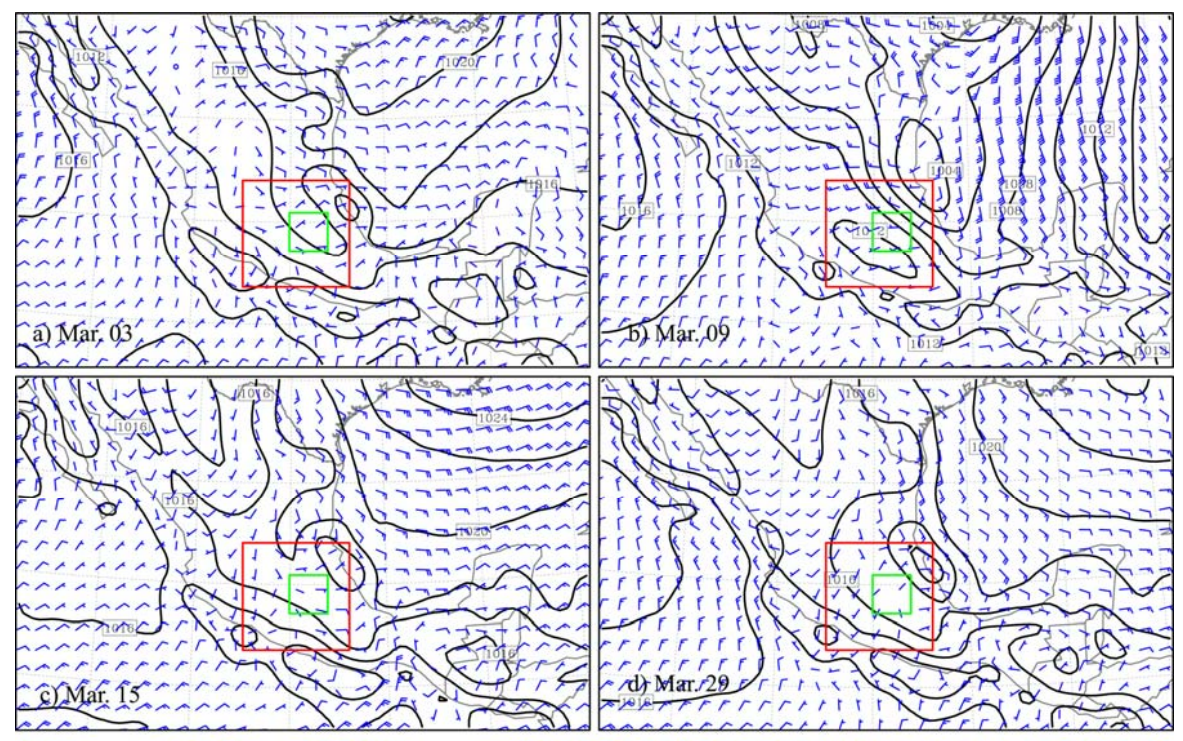

Fig. 4. Same as in Fig. 3, but for surface pressure and winds.

is a "South-Venting" day, with northeast winds aloft and strong southward transport at the surface. An anti-cyclone on $700 \mathrm{hPa}$ over the border of Mexico and US (Fig. 3a) leads to northeast winds over the Mexico City basin. The prevailing south winds on surface are influenced by the high pressure system on the north (Fig. 4a). 9 March represents an " $\mathrm{O}_{3}$ North" day, with stronger southwest winds over the basin rim and a north-south convergence zone. An anti-cyclone is located at the southwest of Mexico along the Pacific Ocean coast on $700 \mathrm{hPa}$ (Fig. 3b), causing a divergence zone over
Mexico City. During the daytime, a weak surface high is over Mexico City, and finally replaced by the local wind circulation (Fig. 4b). 15 March is an "O $\mathrm{O}_{3}-$ South" day when an anticyclone on $700 \mathrm{hPa}$ is located in the Gulf of Mexico (Fig. 3c), producing the southeast wind aloft. When north surface winds meet the southeast gap flow in the afternoon (Fig. 4c), an east-west convergence zone is formed and moving northwards in the evening. 29 March is classified as "Convection-North", which represents weak southerly winds aloft and rain in the northern part of the basin. An 

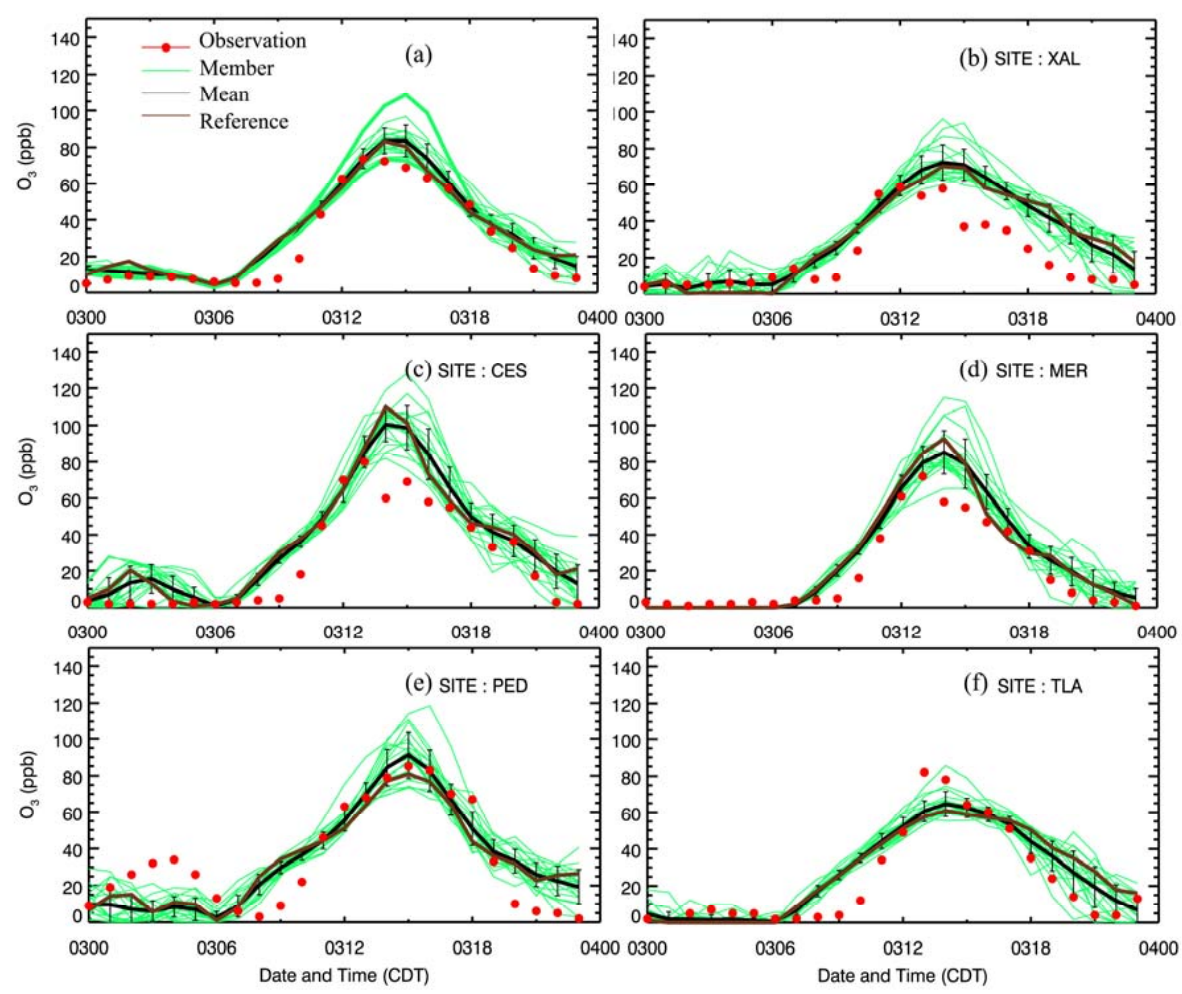

Fig. 5. Temporal evolution of surface $\left[\mathrm{O}_{3}\right]$ (ppb) from each ensemble member (thin green lines), ensemble mean (bold black line) and reference deterministic forecast (bold orange line) of the CTRL ensemble simulation (3 March 2006) and observations (red dots) for values (a) averaged over the RAMA sites and (b-f) at the 5 selected stations (TLA, XAL, MER, PED, and CES, shown in Fig. 1b). The error bars denote the ensemble spread. Bold green lines in (a) indicate two extreme cases (low ozone case: EN-11 and high ozone case: EN-14).

anti-cyclone on $700 \mathrm{hPa}$ over Mexico and the Gulf of Mexico (Fig. 3d) leads to subsidence over the Mexico City basin. The wind circulation on the surface is mostly affected by local topography (Fig. 4d). The convergence develops during daytime while the divergence occurs at nighttime and early morning due to the surrounding mountain areas.

\section{Control ensemble simulation}

\subsection{Overview of the control ensemble performance}

Figure 5a shows the temporal evolution of the ensemble mean and spread of the surface $\left[\mathrm{O}_{3}\right]$ averaged at the Ambient Air Monitoring Network sites (squares shown in Fig. 1b, referred as RAMA sites in the following text) in the Mexico City basin. Figure $5 b-f$ presents the diurnal cycle of the ensemble mean and spread of the surface $\left[\mathrm{O}_{3}\right]$ at selected five single stations (XAL, CES, MER, PED, and TLA, denoted in Fig. 1b). Whether for the average over the RAMA sites or at the single stations, the ensemble mean captures reasonably well the sharp buildup of the $\left[\mathrm{O}_{3}\right]$ in the morning and early afternoon. However, the ensemble mean tends to overestimate the $\left[\mathrm{O}_{3}\right]$ during the afternoon, especially dur- ing the peak $\mathrm{O}_{3}$ period. The ensemble spread of the simulated surface $\left[\mathrm{O}_{3}\right]$ averaged over the RAMA sites can reach up to $10 \mathrm{ppb}$ (Fig. 5a) during peak $\mathrm{O}_{3}$ period. In general, the ensemble spreads of the surface $\left[\mathrm{O}_{3}\right]$ vary and are much bigger at the selected five single stations (Fig. 5b-f), with the maximum exceeding $15 \mathrm{ppb}$. The observations are principally within the spread of the ensemble simulations, while the ensemble mean is slightly higher than the observations but generally better than the reference deterministic forecast, indicating that the predictability limit on $\mathrm{O}_{3}$ predictions may still exist in the ensemble simulations.

Figure 6 shows the temporal evolution of the ensemble mean of the surface $\mathrm{O}_{3}$ distributions along with the ensemble mean wind vectors in the Mexico City basin and the surrounding area simulated by the CNTL ensemble. At the initial time (00:00 CDT), the lower ensemble mean $\mathrm{O}_{3}$ area is located within the urban area of the Mexico City basin due to the titration from NO emissions and the lack of photochemical activities and continues until early morning (06:00 CDT). From 06:00 to 12:00 CDT, $\mathrm{O}_{3}$ concentration inside the basin increases due to the light southerly winds and increasing photochemical activities. From 12:00 to 15:00 CDT, a convergence zone is formed in the southwest of the Mexico City basin with increasing northerly wind, 

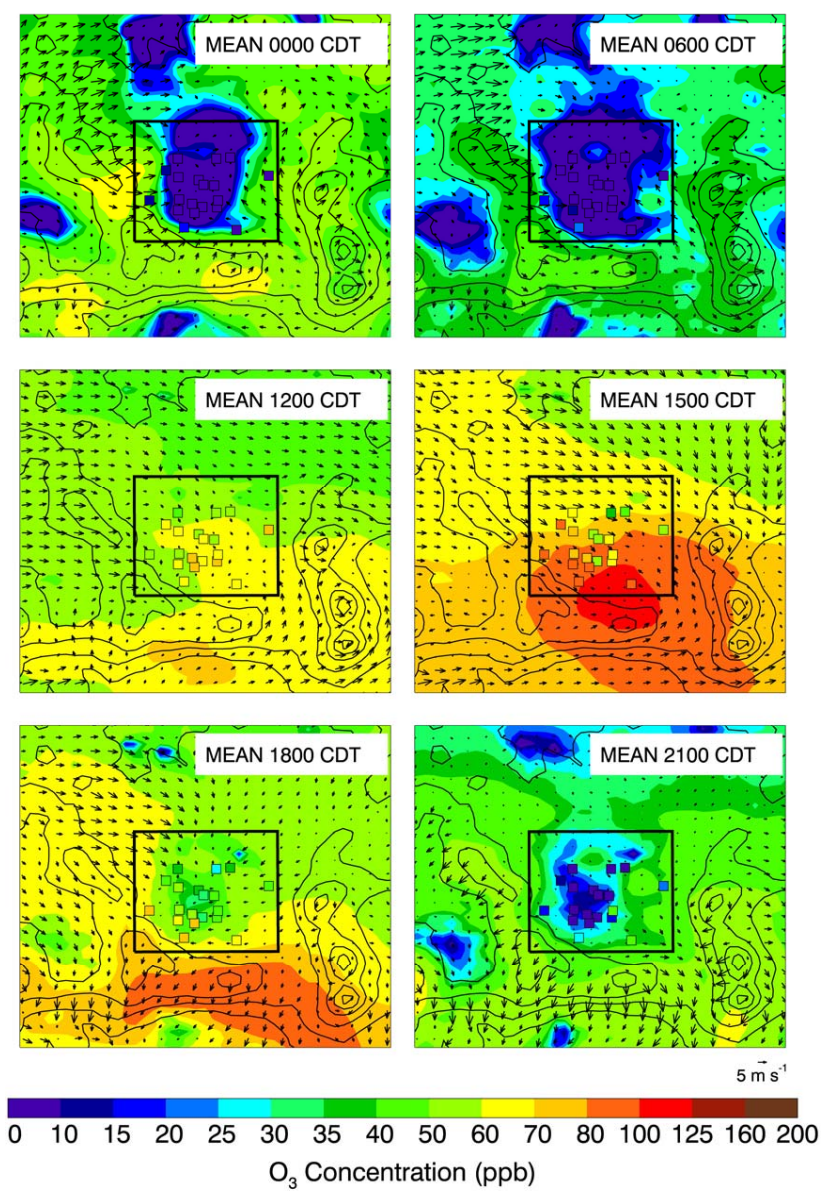

Fig. 6. Ensemble mean (color) of the surface $\left[\mathrm{O}_{3}\right](\mathrm{ppb})$ distributions along with the ensemble mean winds valid at 00:00 CDT, 06:00 CDT, 12:00 CDT, 15:00 CDT, 18:00 CDT, and 21:00 CDT of the CNTL ensemble simulations (3 March 2006). The colored squares denote the ozone measurements from the RAMA sites. Inner box denotes the domain used for Fig. 7.

leading to the occurrence of maximum $\left[\mathrm{O}_{3}\right]$ inside the basin around 15:00 CDT, which is consistent with the observations from the RAMA sites (squares). From 15:00 to 18:00 CDT, the high ensemble mean $\mathrm{O}_{3}$ area moves southward along with the increased northerly winds. Toward the end of the day (21:00 CDT), the ensemble mean of $\mathrm{O}_{3}$ decreases again inside the basin.

Figure 7 shows the surface winds measured at the RAMA sites along with the simulated ensemble mean surface winds in the basin around the $\mathrm{O}_{3}$ peak time. In general, the ensemble mean of surface winds agree better with measurements inside the basin than those in the surroundings. However, the discrepancies between the ensemble mean and observations are still obvious, which could be caused by the systematic errors in the meteorological models. Another important reason could be the $3-\mathrm{km}$ horizontal resolution used in our simulations. Basically, the effective resolution in numerical simulations is about 7 times of the horizontal resolution
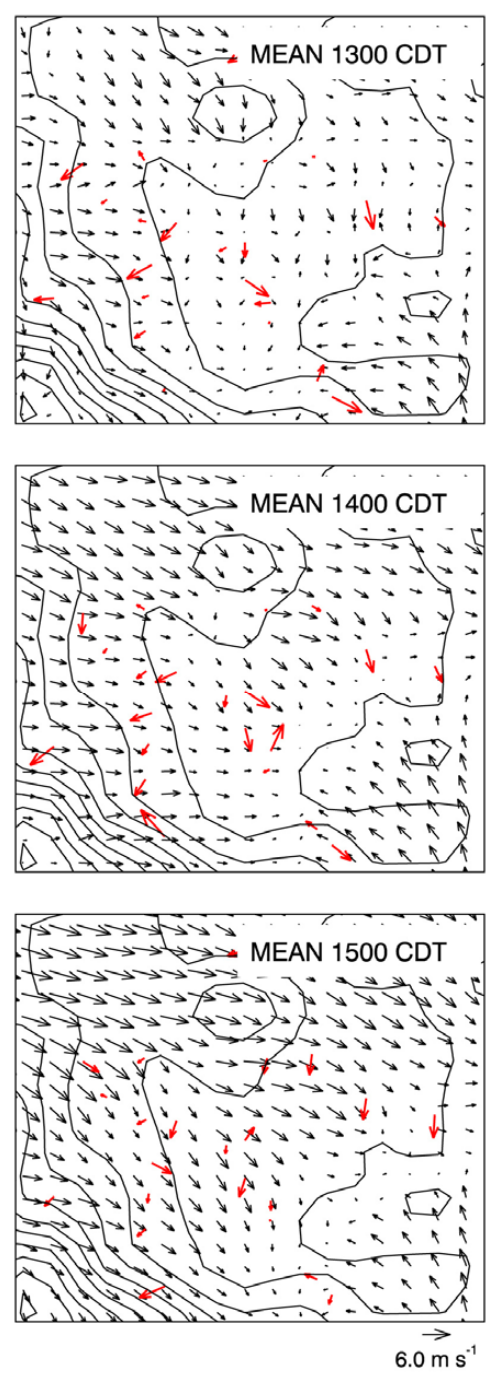

Fig. 7. Ensemble mean (black arrows) of the surface winds along with the measurements (red arrows) at the RAMA sites around the Mexico City basin for 13:00 CDT, 14:00 CDT, and 15:00 CDT on 3 March 2006.

used in the model (Skamarock, 2004), which corresponds to $21 \mathrm{~km}$ in our case. It should be noted that the distances between most of the RAMA sites are less than $21 \mathrm{~km}$; therefore higher-resolution simulations might be necessary to capture the basin scale phenomenon. In addition, the measured surface wind directions are often disturbed by city buildings, especially in large cities, which generally cannot represent the prevailing synoptic scale wind direction.

\subsection{Uncertainties during peak ozone period}

Although the initial meteorological uncertainties (used in our study, see Fig. 2) are smaller than typical observational and analysis errors, our ensemble forecasts demonstrate that large uncertainties in $\mathrm{O}_{3}$ prediction, especially during peak $\mathrm{O}_{3}$ period (12:00-18:00 CDT), are possible (see Fig. 5a). 

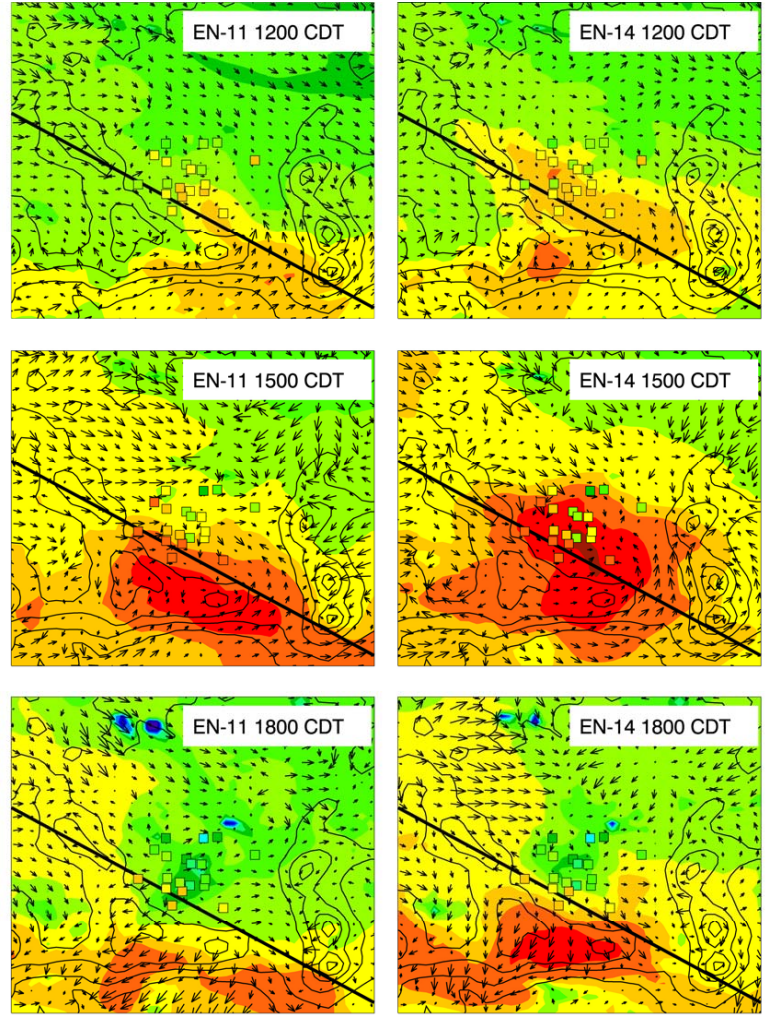

$5 \overrightarrow{\mathrm{ms}}$

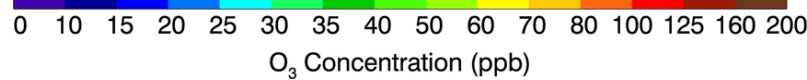

Fig. 8. Surface $\left[\mathrm{O}_{3}\right]$ of two extreme members (EN-11 and EN-14, bold green lines shown in Fig. 5a) along with surface wind vectors valid at 12:00 CDT, 15:00 CDT, and 18:00 CDT on 3 March 2006. Cross line is the position of the cross-section shown in Fig. 9.

To illustrate the discrepancy between different ensemble members, we have chosen two ensemble members: EN-11 and EN-14, which represent the lowest and highest $\left[\mathrm{O}_{3}\right]$ averaged over the RAMA sites, respectively (bold green lines shown in Fig. 5a). Figure 8 presents the horizontal distributions of the surface $\left[\mathrm{O}_{3}\right]$ along with surface winds from $\mathrm{EN}-11$ and EN-14. The striking discrepancies in the surface winds between these two extreme members are attributed principally to the remarkable variations in $\mathrm{O}_{3}$ distributions in the Mexico City basin. As shown in the upper panels of Fig. 8, before peak $\mathrm{O}_{3}$ time, the stronger (weaker) northwest surface winds in the basin transport more (less) $\mathrm{O}_{3}$ precursors outside of the Mexico City basin in EN-11 (EN-14). At peak $\mathrm{O}_{3}$ time (middle panels), the northwest surface winds remain stronger (weaker) in EN-11 (EN-14) in the basin but the southerly gap winds are weaker (stronger) in EN-11 (EN14), so less (more) $\mathrm{O}_{3}$ and its precursors accumulate inside the basin in EN-11 (EN-14). After peak $\mathrm{O}_{3}$ time (bottom panels), the $\mathrm{O}_{3}$ plumes in both cases move outside of the basin with the organized northeast winds.
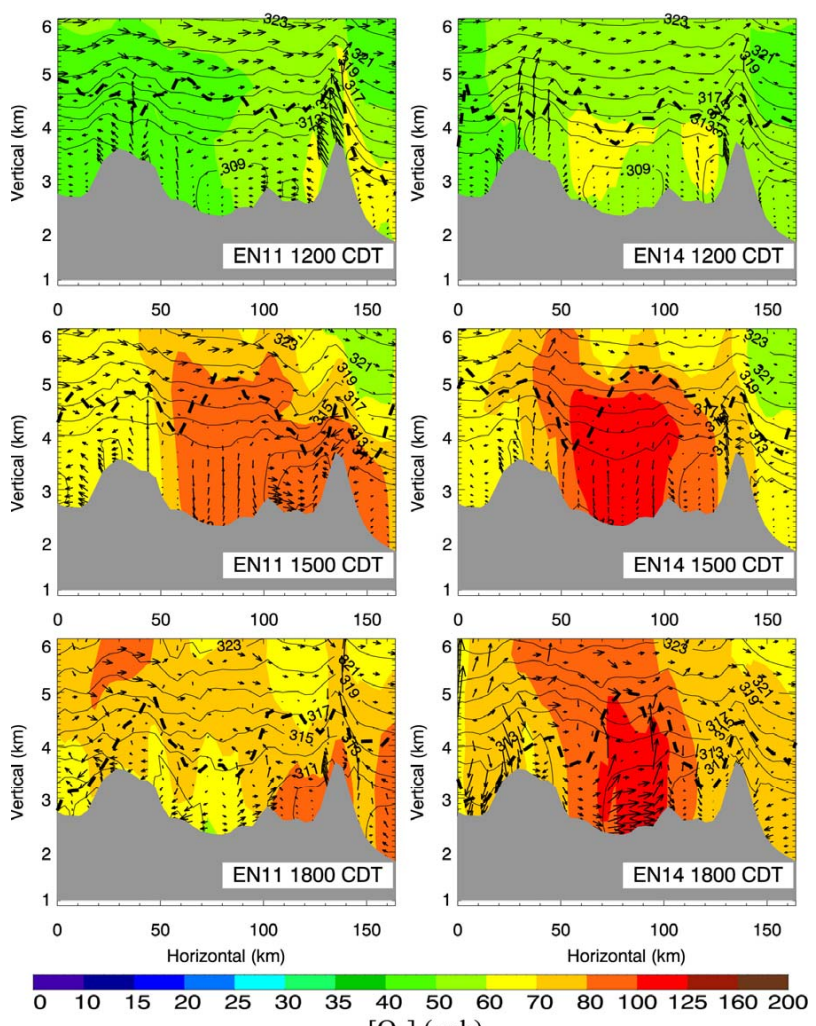

$\left[\mathrm{O}_{3}\right](\mathrm{ppb})$

Fig. 9. Cross-section of $\left[\mathrm{O}_{3}\right]$ (ppb, shading), wind vectors, potential temperature $(\mathrm{K}$, contours), and PBL height ( $\mathrm{km}$, bold dash line) of two extreme members (EN-11 and EN-14) valid at 12:00 CDT, 15:00 CDT, and 18:00 CDT on 3 March 2006 along the cross line denoted in Fig. 8.

The vertical distributions of $\left[\mathrm{O}_{3}\right]$, potential temperature, wind vectors, and PBL height further demonstrate the large discrepancies between EN-11 and EN-14 (Fig. 9). Before peak $\mathrm{O}_{3}$ time (upper panels), both southeast low-level winds and northwest upper-level winds are stronger (weaker) in EN-11 (EN-14) over the basin, causing less (more) $\mathrm{O}_{3}$ precursors inside the Mexico City basin in EN-11 (EN-14). At peak $\mathrm{O}_{3}$ time (middle panels), both low-level winds and upper-level winds remain stronger in EN-11 than in EN-14 and hence more $\mathrm{O}_{3}$ precursors are transported outside of the basin in $\mathrm{EN}-11$ than in $\mathrm{EN}-14$. More $\mathrm{O}_{3}$ precursors and higher temperature in EN-14 are favorable for the $\mathrm{O}_{3}$ formation in the basin. After peak $\mathrm{O}_{3}$ time (bottom panels), the plumes in both members commence to decay due to the intensified upslope winds.

\subsection{Connections between meteorological uncertainties and ozone prediction uncertainties}

Meteorological conditions, such as wind fields, temperature, water vapor mixing ratio and PBL, have direct impacts on air quality simulation (Seaman, 2000). The ensemble simulations are a good technique to examine the relationship 

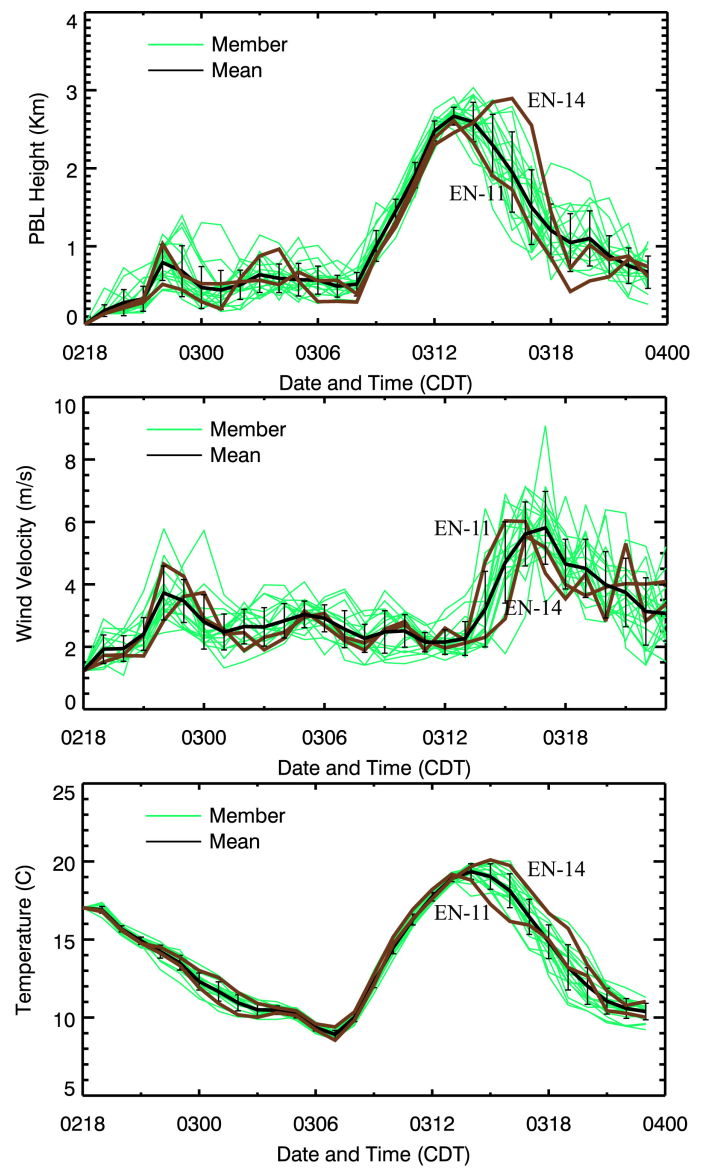

Fig. 10. Temporal evolution of the PBL height ( $\mathrm{km}$, top panel), wind speed $\left(\mathrm{m} / \mathrm{s}\right.$, middle panel), and surface temperature $\left({ }^{\circ} \mathrm{C}\right.$, bottom panel) from each ensemble member (thin green lines) and ensemble mean (bold black line) of the CTRL ensemble simulation (3 March 2006), two bold orange lines indicate two extreme members (EN-11 and EN-14).

between the uncertainties in meteorological fields and the uncertainties in $\mathrm{O}_{3}$ simulations. Figure 10 shows the temporal evolution of the ensemble mean and the spread of the PBL height, wind speed, and surface temperature averaged over the RAMA sites from the initial time of the meteorological model $(6 \mathrm{~h}$ earlier than the initial time of the photochemical model). The ensemble spreads of these variables are initially small but gradually grow with the integration time. However, during the morning hours (08:00-12:00 CDT), the ensemble spreads of the above-mentioned meteorological variables are small compared with those in other periods, also leading to smaller ensemble spread of $\left[\mathrm{O}_{3}\right]$ for this period. During peak $\mathrm{O}_{3}$ period (12:00-18:00CDT), the maximum ensemble spreads of the wind speed, PBL height, and surface temperature are about $1.25 \mathrm{~m} \mathrm{~s}^{-1}, 0.5 \mathrm{~km}$, and $1.5 \mathrm{~K}$, respectively, and are much larger than those during other periods, demonstrating that the large $\mathrm{O}_{3}$ prediction uncertainties are attributable to the large meteorological uncertainties. The ensemble spreads of PBL heights and wind speeds start to

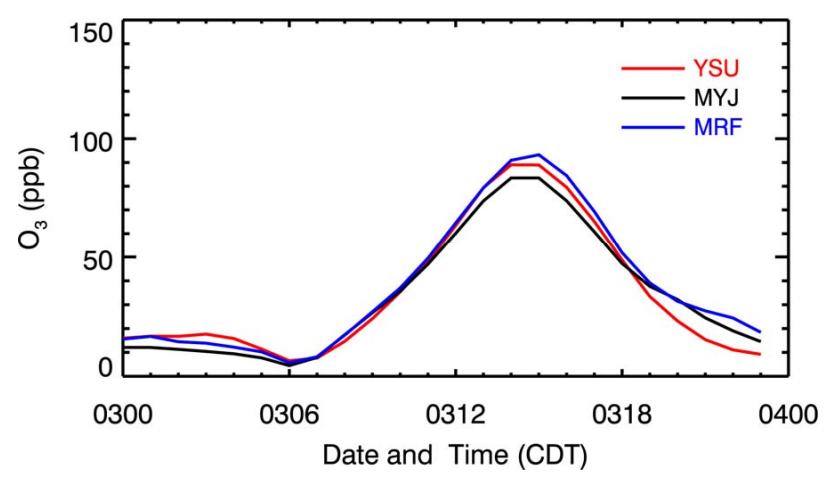

Fig. 11. Temporal evolution of the ensemble mean surface $\left[\mathrm{O}_{3}\right]$ averaged over the RAMA sites using three different PBL schemes (YSU, MYJ, and MRF scheme).

increase from 12:00 CDT, which corresponds well to the enhancement of the ensemble spread of $\left[\mathrm{O}_{3}\right]$. The PBL height and wind speed affect the surface $\left[\mathrm{O}_{3}\right]$ through vertical and horizontal transport of pollutants. The convergence caused by the wind circulation determines the location and the level of the high $\mathrm{O}_{3}$ plume as mentioned in the previous section. All of these factors are combined to alter the $\mathrm{O}_{3}$ distributions. For example, we have highlighted the two extreme members (EN-11 and EN-14) in Fig. 10 (bold brown lines). In the low $\mathrm{O}_{3}$ case (EN-11), the lower PBL height, higher wind speed, and lower surface temperature, jointly provide an unfavorable condition for the $\mathrm{O}_{3}$ formation, and vice versa in the high $\mathrm{O}_{3}$ case $(\mathrm{EN}-14)$.

\section{Effects of PBL parameterization schemes}

The PBL is responsible for vertical sub-grid-scale fluxes due to eddy transports in the whole atmospheric column, not just the boundary layer. The PBL schemes determine the flux profiles within the well-mixed boundary layer and the stable layer, and thus provide atmospheric trends of temperature, moisture (including clouds), and horizontal momentum in the entire atmospheric column (Skamarock et al., 2005). WRF ARW v2.1.1 includes MRF, YSU, and MYJ schemes. The MRF scheme employs a counter-gradient flux for heat and moisture in unstable conditions. The PBL height is determined from a critical bulk Richardson number. The YSU scheme is the next generation of the MRF scheme, which also uses the counter-gradient terms to represent fluxes due to non-local gradients. The PBL height is defined from buoyancy profile. MYJ scheme represents a nonsingular implementation of the Mellor-Yamada Level 2.5 turbulence closure model (Mellor and Yamada, 1982) through the full range of atmospheric turbulent regimes. PBL height is derived from the prognostic turbulent kinetic energy (TKE) equation (Skamarock et al., 2005). 

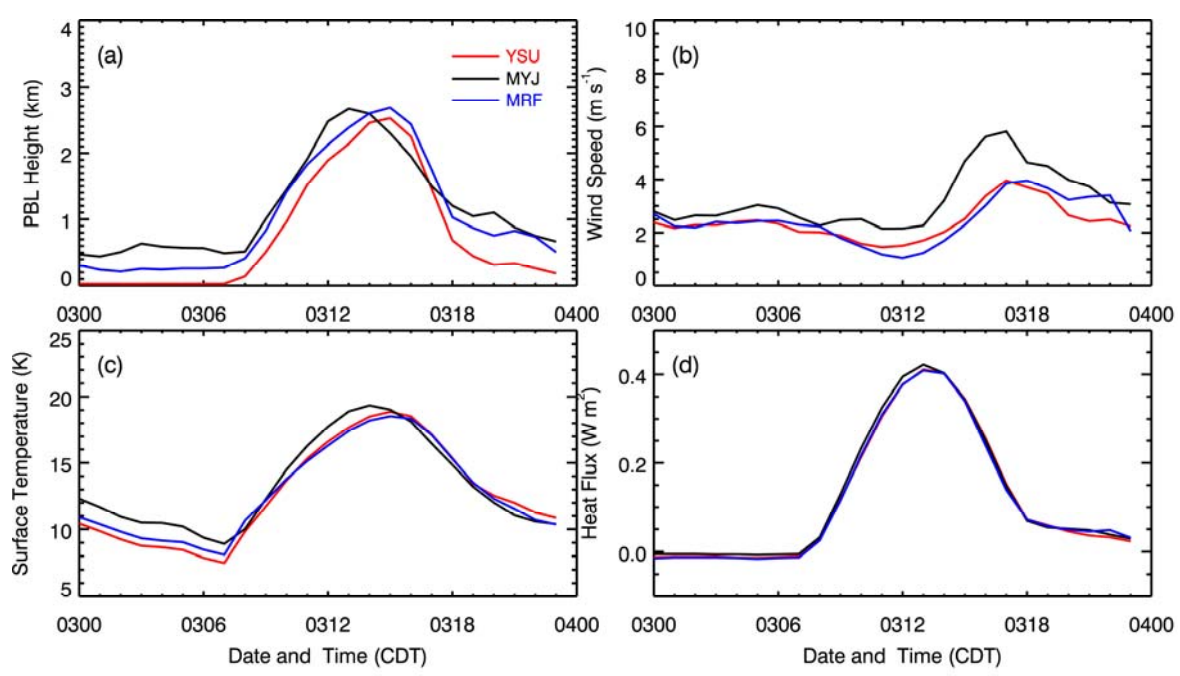

Fig. 12. Same as in Fig. 11, but for (a) PBL height, (b) surface wind speed, (c) surface temperature, and (d) surface heat flux.

In order to investigate the impact of different PBL parameterization schemes on the $\mathrm{O}_{3}$ simulation, we have conducted ensemble forecasts using two other PBL schemes, the YSU PBL scheme and the MRF PBL scheme coupled with MoninObukhov surface layer scheme (Monin and Obukhov, 1954), in addition to the MYJ PBL scheme coupled with MYJ surface layer scheme (Janjic, 1996, 2002) used in the control case. All the PBL schemes are coupled with Noah land surface model (Chen and Dudhia, 2001).

Figure 11 shows the temporal evolution of the ensemble mean of the surface $\left[\mathrm{O}_{3}\right]$ averaged over the RAMA sites simulated by three different PBL schemes (YSU, MYJ, and MRF scheme). The differences in $\mathrm{O}_{3}$ simulations from different PBL schemes mainly appear from midnight to early morning hours (00:00-06:00 CDT), during peak $\mathrm{O}_{3}$ hours (13:0017:00 CDT), and at nighttime (19:00-23:00 CDT). During 00:00-06:00 CDT, the $\mathrm{O}_{3}$ simulation by MYJ scheme is notably better than those by YSU scheme and MRF scheme. The MRF scheme yields the highest peak $\left[\mathrm{O}_{3}\right]$ while the MYJ scheme predicts the lowest peak $\left[\mathrm{O}_{3}\right]$. During peak $\mathrm{O}_{3}$ time, the difference of $\left[\mathrm{O}_{3}\right]$ among the three PBL schemes is about $5-10 \mathrm{ppb}$, slightly less than those caused by initial condition uncertainties. The ensemble spread of simulated surface $\left[\mathrm{O}_{3}\right]$ averaged over the RAMA sites also varies with different PBL schemes (not shown). The ensemble spread of peak time $\left[\mathrm{O}_{3}\right]$ with the YSU scheme is slightly smaller than that with the MRF scheme but larger than that with the MYJ scheme (not shown). The temporal evolutions of the PBL height, wind speed, surface temperature, and surface heat flux using the above three PBL schemes are shown in Fig. 12. The surface wind speed and PBL height vary greatly between different PBL schemes (Fig. 12a, b). The maximum difference of the PBL height occurs during nighttime (18:0023:00 CDT) and early morning hours (00:00-07:00 CDT). The surface wind speed has the maximum difference dur-
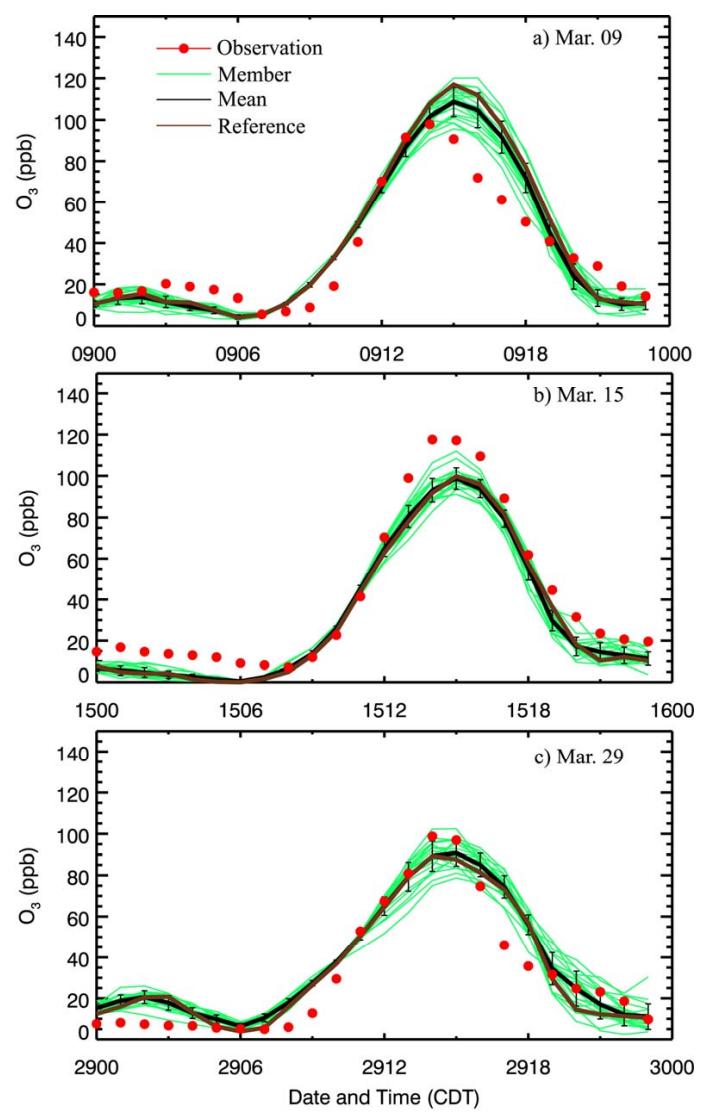

Fig. 13. Same as in Fig. 5a, but for 9, 15, and 29 March 2006.

ing late afternoon (15:00-18:00 CDT). The surface temperature has bigger difference from midnight to early morning (00:00-07:00 CDT). The surface heat flux due to the surface layer scheme varies slightly (Fig. 12d). These meteorological fields combine to affect the $\mathrm{O}_{3}$ simulations. 

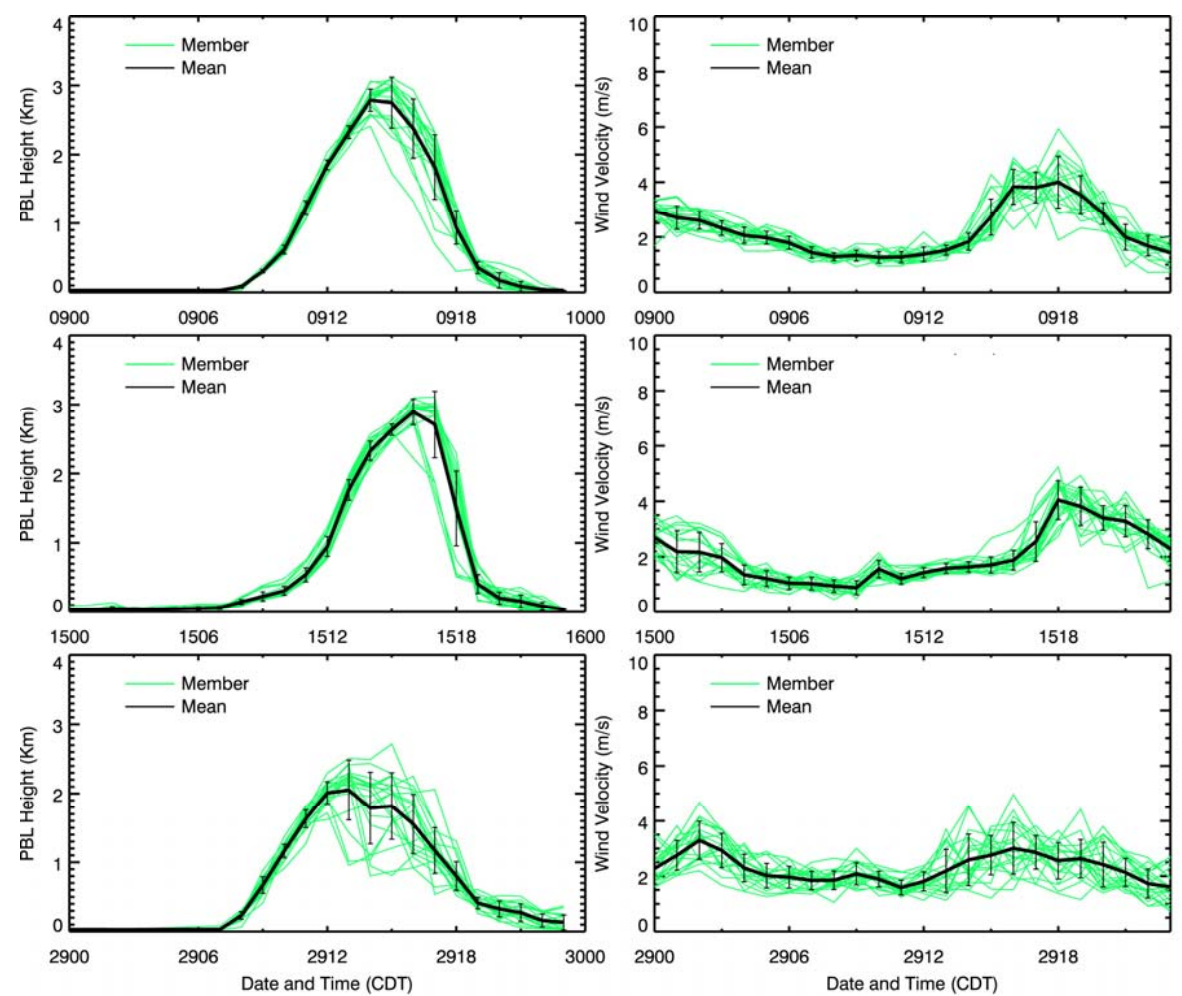

Fig. 14. Temporal evolution of the PBL height and surface wind speed from each ensemble member (thin green lines) and ensemble mean on different days $(9,15$, and 29 March).

\section{The ensemble simulations on other episodes}

In order to explore the impacts of meteorological uncertainties on $\mathrm{O}_{3}$ predictability under different meteorological conditions, we have further conducted ensemble forecasts on 9 , 15 , and 29 March, which represent three other typical $\mathrm{O}_{3}$ pollution episodes ("O $\mathrm{O}_{3}$-North", "O${ }_{3}$-South" and "ConvectionNorth") in the Mexico City basin (de Foy et al., 2008), using both meteorological and photochemical models.

Figure 13 shows the temporal evolutions of simulated ensemble mean and spread of the surface $\left[\mathrm{O}_{3}\right]$ averaged over the RAMA sites versus the observations on these three days. The temporal evolutions of the ensemble means generally agree with observations, although the peak time $\mathrm{O}_{3}$ are sometimes overestimated or underestimated, and the peak times also differ by one or two hours. The ensemble means are mostly better than the reference deterministic forecasts (such as 9 and 29 March), but the ensemble spreads vary under different episodes. The maximum ensemble spreads during peak $\mathrm{O}_{3}$ hours on 9,15 , and 29 March are $8 \mathrm{ppb}, 5 \mathrm{ppb}$, and $7 \mathrm{ppb}$, respectively, slightly smaller than that of 3 March, but still significant compare with the ensemble mean. As discussed in the previous sections, the large $\mathrm{O}_{3}$ prediction uncertainties are related to the large meteorological uncertainties. We have analyzed the ensemble means and spreads of the surface wind speed and PBL height for these three days (Fig. 14). The meteorological uncertainties (error bar in the figure) are also larger during peak $\mathrm{O}_{3}$ time (12:0018:00 CDT). The day with the larger (smaller) meteorological uncertainties generally corresponds to the larger (smaller) $\mathrm{O}_{3}$ uncertainties.

The $\mathrm{O}_{3}$ predictabilities for different episodes seem to be different, e.g., 15 March has the smallest spread during the peak $\mathrm{O}_{3}$ period. The practical predictability of the atmosphere is caused by model errors and initial conditions uncertainties, and the error growth in the model depends on the flow regime (see e.g., Nuss and Miller, 2001; Zhang et al., 2007b). In our case, since we have used the same model and set up for all selected days, the differences in predictabilities can only be caused by the different flow regime. In addition, as mentioned in Sect. 3, 15 March is an "O ${ }_{3}$-SOUTH" day, with weak synoptic forcing and a much clearer signature of terrain-induced flow (such as gap flow). The initial perturbations used in our study only include the large scale uncertainties, and might not represent the small scale initial error well. Therefore, the ensemble mean $\left[\mathrm{O}_{3}\right]$ is almost the same as the reference deterministic forecast during the peak $\mathrm{O}_{3}$ period. The discrepancy between the ensemble mean and the observations on this day is also larger than that for the other 3 days. 
While the ensemble mean provides better magnitude of simulated $\left[\mathrm{O}_{3}\right]$, the timing of the peak $\mathrm{O}_{3}$ is only slightly improved on these days. One possible reason could be the model errors or emission uncertainties as described in the previous section since meteorological initial condition uncertainty is only one of several known sources of significant photochemical model errors (Hanna et al., 2001).

\section{Conclusions}

We have investigated the $\mathrm{O}_{3}$ predictability due to meteorological uncertainties by conducting meteorological and photochemical ensemble simulations in the Mexico City basin on four selected days. We focus on the uncertainties in meteorological simulations caused by initial condition errors and PBL schemes. The initial ensemble is generated with the WRF-3DVAR system. The background error statistics are defined by the domain-specific climatological background error covariance, which are derived from one-month simulations in the same domain using NMC method. The selected four days $(3,9,15$, and 29 March 2006) represent four different meteorological episodes in the Mexico City basin. We choose 3 March 2006 as a control run to analyze the results.

Over the 24-h simulation, the ensemble mean in the control run compare reasonably well with the observations, including the maximum $\left[\mathrm{O}_{3}\right]$, the sharp buildup of $\left[\mathrm{O}_{3}\right]$ in the morning and early afternoon, and the transport of the plume. The ensemble spread of simulated surface $\left[\mathrm{O}_{3}\right]$ averaged over the RAMA sites can reach up to $10 \mathrm{ppb}$. The increasing uncertainties in meteorological fields during peak $\mathrm{O}_{3}$ period contribute to the largest unpredictability in $\mathrm{O}_{3}$ simulations. Generally, the impacts of the wind speed and PBL height on $\left[\mathrm{O}_{3}\right]$ are more straightforward, via the horizontal and vertical transport of pollutants, while the impacts of temperature and water vapor are mostly indirect. These factors combine to affect the $\mathrm{O}_{3}$ variations and distributions.

The uncertainties in the $\mathrm{O}_{3}$ prediction vary with the PBL scheme used in the model, which influences the PBL height, wind, and temperature, and hence alters the $\mathrm{O}_{3}$ simulation results. The differences in $\mathrm{O}_{3}$ simulations caused by different PBL schemes mainly occur during nighttime, early morning hours, and peak $\mathrm{O}_{3}$ hours, and can reach 5-10 ppb. Based on the simulations on four selected days, the ensemble spread of surface $\mathrm{O}_{3}$ concentrations also varies with different meteorological episodes, indicating that the relationship between the uncertainties in meteorological fields and $\mathrm{O}_{3}$ predictions is flow-dependent and complicated. The day with the larger (smaller) meteorological uncertainties generally corresponds to the larger (smaller) $\mathrm{O}_{3}$ uncertainties. The different predictability on different day shown in our study is mostly due to the different flow regime on different day.

However, some of the discrepancies between the ensemble mean and the observations can be explained by the systematic errors in both meteorological and photochemical models and the uncertainties in the emission inventory. The horizontal resolution used in the present study may also confine the investigation of the basin scale phenomenon. On the other hand, analysis inaccuracies are inevitable even with ample observations. Therefore ensemble simulations should be used to span the range of possible outcomes consistent with the meteorological situations on a given day. An ensemble forecasting system, incorporating as many sources of error (such as the uncertainties in meteorological initial conditions, models, and emissions) as possible, can provide guidance on both the most likely $\mathrm{O}_{3}$ evolution and also the range of possibilities (Zhang et al., 2007a).

Acknowledgements. We are indebted to the large number of people involved in the MILAGRO field campaign as well as those involved in long-term air quality monitoring and the emissions inventory in the Mexico City metropolitan area, which made this study possible. The authors gratefully acknowledge financial support from the US National Science Foundation (ATM-0810931) and the Molina Center for Energy and the Environment. We would like to thank Yonghui Weng at Penn State University and Zhiyong Meng at Peking University for their help in the implementation of the ensemble simulations. Acknowledgment is also made to the National Center for Atmospheric Research, which is sponsored by the National Science Foundation, for the computing time used in this research.

Edited by: S. Madronich

\section{References}

Anthes, R. A., Kuo, Y. H., Baumhefner, D. P., Eriico, R. P., and Bettge, T. W.: Predictability of mesoscale of atmospheric motions, Adv. Geophys., 28B, 159-202, 1985.

Alapaty, K., Raman S., and Madala R. V.: Investigation of the role of the boundary layer processes in an active monsoon using a mesoscale model, Bound.-Lay. Meteor., 67, 407-426, 1994.

Barker, D. M., Huang, W., Guo, Y.-R., Bourgeois, A. J., and Xiao, Q. N.: A three-dimensional variational data assimilation system for MM5: Implementation and initial results, Mon. Weather Rev., 132, 897-914, 2004.

Barker, D. M.: Southern high-latitude ensemble data assimilation in the Antarctic mesoscale prediction system, Mon. Weather Rev., 133, 3431-3449, 2005.

Bei, N. and Zhang, F.: Impacts of initial condition errors on mesoscale predictability of heavy precipitation along the Mei-Yu front of China, Q. J. Roy. Meteorol. Soc., 133, 83-99, 2007.

Bei, N., de Foy, B., Lei, W., Zavala, M., and Molina, L. T.: Using 3DVAR data assimilation system to improve ozone simulations in the Mexico City basin, Atmos. Chem. Phys., 8, 7353-7366, doi:10.5194/acp-8-7353-2008, 2008.

Bossert, J. E.: An investigation of flow regimes affecting the Mexico City region, J. Appl. Meteorol., 36, 119-140, 1997.

Buizza, R., Tribbia J., Molteni F., and Palmer T.: Computation of optimal unstable structures for a numerical weather prediction model, Tellus, 45A, 388-407, 1993. 
Buizza, R.: Potential forecast skill of ensemble prediction and spread and skill distributions of the ECMWF ensemble prediction system, Mon. Weather Rev., 125, 99-119, 1997.

Chen, F. and Dudhia, J.: Coupling an advanced landsurface/hydrology model with the Penn State/NCAR MM5 modeling system. Part I: Model description and implementation, Mon. Weather Rev., 129, 569-585, 2001.

Dabberdt, W. F., Carroll, M. A., Baumgardner, D., et al.: Meteorological research needs for improved air quality forecasting: Report of the 11th Prospectus Development Team of the U.S. Weather Research Program, technical report, Natl. Cent. For Atmos. Res., Boulder, Colo, 2003.

de Foy, B., Caetano, E., Magaña, V., Zitácuaro, A., Cárdenas, B., Retama, A., Ramos, R., Molina, L. T., and Molina, M. J.: Mexico City basin wind circulation during the MCMA-2003 field campaign, Atmos. Chem. Phys., 5, 2267-2288, doi:10.5194/acp-52267-2005, 2005.

de Foy, B., Clappier, A., Molina, L. T., and Molina, M. J.: Distinct wind convergence patterns in the Mexico City basin due to the interaction of the gap winds with the synoptic flow, Atmos. Chem. Phys., 6, 1249-1265, doi:10.5194/acp-6-1249-2006, 2006a.

de Foy, B., Varela, J. R., Molina, L. T., and Molina, M. J.: Rapid ventilation of the Mexico City basin and regional fate of the urban plume, Atmos. Chem. Phys., 6, 2321-2335, doi:10.5194/acp-6-2321-2006, 2006b.

de Foy, B., Fast, J. D., Paech, S. J., Phillips, D., Walters, J. T., Coulter, R. L., Martin, T. J., Pekour, M. S., Shaw, W. J., Kastendeuch, P. P., Marley, N. A., Retama, A., and Molina, L. T.: Basinscale wind transport during the MILAGRO field campaign and comparison to climatology using cluster analysis, Atmos. Chem. Phys., 8, 1209-1224, doi:10.5194/acp-8-1209-2008, 2008.

Delle Monache, L. and Stull, R.: An ensemble air quality forecast over western Europe during an ozone forecast, Atmos. Environ., 37, 3469-3474, 2003.

Delle Monache, L., Deng, X., Zhou, Y., and Stull, R.: Ozone ensemble forecasts: 1: A new ensemble design, J. Geophys. Res., 111, D05307, doi:10.1029/2005JD006310, 2006a.

Delle Monache, L., Nipen, T., Deng, X., Zhou, Y., and Stull, R.: Ozone ensemble forecasts: 2: A Kalman-filter predictor bias correction, J. Geophys. Res., 111, D05038, doi:10.1029/2005JD006311, 2006b.

Doran, J. C. and Zhong, S.: Thermally driven gap winds into the Mexico City basin, J. Appl. Meteorol., 39, 1330-1340, 2000.

ENVIRON International Corporation: Users Guide to the Comprehensive Air Quality. Model with Extensions (CAMx) version 4.40, available online at: http://www.camx.com, 2006.

Errico, R. M. and Baumhefner, D. P.: Predictability experiments using a high-resolution limited-area model, Mon. Weather Rev., 115, 488-504, 1987.

Fast, J. D. and Zhong, S.: Meteorological factors associated with inhomogeneous s within the Mexico City basin, J. Geophys. Res., 103, 18927-18946, 1998.

Fast, J. D., de Foy, B., Acevedo Rosas, F., Caetano, E., Carmichael, G., Emmons, L., McKenna, D., Mena, M., Skamarock, W., Tie, X., Coulter, R. L., Barnard, J. C., Wiedinmyer, C., and Madronich, S.: A meteorological overview of the MILAGRO field campaigns, Atmos. Chem. Phys., 7, 2233-2257, doi:10.5194/acp-7-2233-2007, 2007.

Galmarini, S., Bianconi, R., Addis, R., et al.: Ensemble dispersion forecasting - Part I: Concept, approach and indicators, Atmos. Environ., 38, 4607-4617, 2004a.

Galmarini, S., Bianconi, R., Klug, W., et al.: Ensemble dispersion forecasting - Part II: Application and evaluations, Atmos. Environ., 38, 4619-4632, 2004b.

Hanna, S. R., Lu, Z. G., Frey, H. C., Wheeler, N., Vukovich, J., Arunachalam, S., Fernau, M., and Hansen, D. A.: Uncertainties in predicted ozone concentrations due to input uncertainties for the UAM-V photochemical grid model applied to the July 1995 OTAG domain, Atmos. Environ., 35, 891-903, 2001.

Hong, S. Y. and Pan, H.-L.: Nonlocal boundary layer vertical diffusion in a medium-range forecast model, Mon. Weather Rev., 124, 2322-2339, 1996.

Hong, S. Y., Dudhia, J., and Chen, S. H.: A revised approach to ice microphical processes for the bulk parameterization of clouds and precipitation, Mon. Weather Rev., 132, 103-120, 2004.

Hou, D., Kalnay, E., and Droegemeier, K. K.: Objective verification of the SAMEX'98 ensemble forecasts, Mon. Weather Rev., 129, 73-91, 2001.

Houtekamer P. L. and Lefaivre, L.: Using Ensemble Forecasts for Model Validation, Mon. Weather Rev. 125, 2416-2426, 1997.

Janjic, Z. I.: The surface layer in the NCEP Eta Model, Eleventh Conference on Numerical Weather Prediction, Norfolk, VA, 1923 August, Amer. Meteor. Soc., Boston, MA, 354-355, 1996.

Janjic, Z. I.: Nonsingular implementation of the Mellor-Yamada level 2.5 scheme in the NCEP Meso Model. NCEP Office Note, 437, 61 pp., 2002.

Jauregui, E.: Heat island development in Mexico City, Atmos. Environ., 31, 3821-3831, 1997.

Jazcilevich, A. D., Garcia, A. R., and Ruiz-Suarez, L. G.: A study of air flow patterns affecting pollutant concentrations in the Central Region of Mexico, Atmos. Environ., 37, 183-193, 2003.

Kain, J. S. and Fritsch, J. M.: Convective parameterization for mesoscale models: The Kain-Fritcsh scheme. The Representation of Cumulus Convection in Numerical Models, Meteor. Monogr., Amer. Meteor. Soc., 46, 165-170, 1993.

Kalnay, E., Atmospheric Modeling, Data Assimilation and Predictability, Cambridge Univ. Press, New York, 341 pp., 2003.

Lei, W., de Foy, B., Zavala, M., Volkamer, R., and Molina, L. T.: Characterizing ozone production in the Mexico City Metropolitan Area: a case study using a chemical transport model, Atmos. Chem. Phys., 7, 1347-1366, doi:10.5194/acp-7-1347-2007, 2007.

Lei, W., Zavala, M., de Foy, B., Volkamer, R., and Molina, L. T.: Characterizing ozone production and response under different meteorological conditions in Mexico City, Atmos. Chem. Phys., 8, 7571-7581, doi:10.5194/acp-8-7571-2008, 2008.

Leith, C. E. and Kraichnan, R. H.: Predictability of turbulent flows, J. Atmos. Sci., 29, 1041-1058, 1972.

Leith, C. E.: Theoretical skill of Monte Carlo forecasts, Mon. Weather Rev., 102, 409-418, 1974.

Lorenz, E. N.: The predictability of a flow which possesses many scales of motion, Tellus, 21, 289-307, 1969.

Mallet, V. and Sportisse, B.: Uncertainty in a chemistry-transport model due to physical parameterizations and numerical approximations: An ensemble approach applied to ozone modeling, J. Geophys. Res., 111, D01302, doi:10.1029/2005JD006149, 2006.

Mao, Q., Gautney, L. L., Cook, T. M., Jacobs, M. E., Smith, S. N., and Kelsoe, J. J.: Numerical experiments on MM5-CMAQ 
sensitivity to various PBL schemes, Atmos. Evniron., 40, 30923110, 2006.

McKeen, S. A., Wilczak, J., Grell, G., et al.: Assessment of an ensemble of seven real-time ozone forecast over eastern North America during the summer of 2004, J. Geophys. Res., 110, D21307, doi:10.1029/2005JD005858, 2005.

Mellor, G. L. and Yamada, T.: Development of a turbulence closure model for geophysical fluid problems, Rev. Geophys. Space Phys., 20, 851-875, 1982.

Meng, Z. and Zhang, F.: Tests of an ensemble Kalman filter for mesoscale and regional-scale data assimilation. Part III: Comparison with 3DVAR in a Real-Data Case Study,Mon. Weather Rev., 136, 522-540, 2008.

Molina, L. T. and Molina, M. J. (eds.): Air Quality in the Mexico Megacity: An Integrated Assessment, Kluwer Academic Publishers, 137-212, 2002.

Molina, L. T., Kolb, C. E., de Foy, B., Lamb, B. K., Brune, W. H., Jimenez, J. L., Ramos-Villegas, R., Sarmiento, J., ParamoFigueroa, V. H., Cardenas, B., Gutierrez-Avedoy, V., and Molina, M. J.: Air quality in North America's most populous city overview of the MCMA-2003 campaign, Atmos. Chem. Phys., 7, 2447-2473, doi:10.5194/acp-7-2447-2007, 2007.

Molina, L. T., Madronich, S., Gaffney, J. S., Apel, E., de Foy, B., Fast, J., Ferrare, R., Herndon, S., Jimenez, J. L., Lamb, B., Osornio-Vargas, A. R., Russell, P., Schauer, J. J., Stevens, P. S., and Zavala, M.: An overview of the MILAGRO 2006 campaign: Mexico City emissions and their transport and transformation, Atmos. Chem. Phys. Discuss., 10, 7819-7983, doi:10.5194/acpd-10-7819-2010, 2010.

Molteni, F., Buizza, R., Palmer, T. N., and Petroliagis, T.: The new ECMWF ensemble prediction system: Methodology and validation, Q. J. Roy. Meteorol. Soc., 122, 73-119, 1996.

Monin, A. S. and Obukhov, A. M.: Basic laws of turbulent mixing in the surface layer of the atmosphere, Contrib. Geophys. Inst. Acad. Sci., USSR, 151, 163-187, 1954 (in Russian).

Mullen, S. L. and Buizza, R.: The impact of horizontal resolution and ensemble size on probabilistic forecasts of precipitation by the ECMWF Ensemble Prediction System, Weather Forecast., 17, 173-191, 2002.

Nielsen-Gammon, J. W., McNider, R. T., Angevine, W. M., White, A. B., and Knupp, K.: Mesoscale model performance with assimilation of wind profiler data: Sensitivity to assimilation parameters and network configuration, J. Geophys. Res., 112, D09119, doi:10.1029/2006JD007633, 2007.

Noh, Y., Cheon, W.-G., Hong, S.-Y., and Raasch, S.: Improvement of the K-profile model for the planetary boundary layer based on large eddy simulation data, Bound.-Lay. Meteorol., 107, 401427, 2003.

Nuss, W. A. and Miller, D. K.: Mesoscale predictability under various synoptic regimes, Nonlin. Processes Geophys., 8, 429-438, doi:10.5194/npg-8-429-2001, 2001.

Pagowski, M., Grell, G. A., Mckeen, S. A., et al.: A simple method to improve ensemble-based ozone forecasts, Geophys. Res. Lett., 32, L07814, doi:10.1029/2004GL022305, 2005.

Parrish, D. F. and Derber, J. C.: The National Meteorological Center's spectral statistical-interpolation analysis system, Mon. Weather Rev., 120, 1747-1763, 1992.

Pielke, R. A. and Uliasz, M.: Use of meteorological models as input to regional and mesoscale air quality models - limitations and strengths, Atmos. Environ., 32, 1455-1466, 1998.

Skamarock, W. C.: Evaluating Mesoscale NWP models using kinetic energy spectra, Mon. Weather Rev., 132, 3019-3032, 2004.

Skamarock, W. C., Klemp, J. B., Dudhia, J., Gill, D. O., Barker, D. M., Wang, W., and Powers, J. G.: A description of the advanced research WRF version 2, NCAR Technical Note, NCAR/TN468+STR, 100 pp., 2005.

Seaman, N. L.: Meteorological modeling for air-quality assessments, Atmos. Environ., 34, 2231-2259, 2000.

Secretaria del Medio Ambiente del Distrito Federal (SMA-DF): Inventario de Emisiones 2006 de la Zona Metropolitana del Valle de México, México, 2008.

Song, J., Lei, W., Bei, N., Zavala, M., de Foy, B., Volkamer, R., Cardenas, B., Zheng, J., Zhang, R., and Molina, L. T.: Ozone response to emission changes: a modeling study during the MCMA-2006/MILAGRO Campaign, Atmos. Chem. Phys., 10, 3827-3846, doi:10.5194/acp-10-3827-2010, 2010.

Stensrud, D. J., Bao, J.-W., and Warner, T. T.: Ensemble forecasting of mesoscale convective systems, paper presented at $12^{\text {th }}$ Conference on Numerical Weather Prediction, Am. Meteorol. Soc., Phoenix, Ariz., 11-16 January, 1998.

Streit, G. E. and Guzman, F.: Mexico City air quality: Progress of an international collaborative project to define air quality management options, Atmos. Environ., 30, 723-733, 1996.

Thomas, S. J., Hacker, J. P., Desgagne, M., and Stull, R.: An enemble analysis of forecast errors related to floating point performance, Weather Forecast., 17, 898-906, 2002.

Tie, X., Madronich, S., Li, G., Ying, Z., Weinheimer, A., Apel, E., and Campos, T.: Simulation of Mexico City plumes during the MIRAGE-Mex field campaign using the WRF-Chem model, Atmos. Chem. Phys., 9, 4621-4638, doi:10.5194/acp-9-4621-2009, 2009.

Tribbia, J. J. and Baumhefner, D. P.: Scale interactions and atmospheric predictability: An updated perspective, Mon. Weather Rev., 132, 703-713, 2004.

Toth, Z. and Kalnay, E.: Ensemble forecasting at NMC: The generation of perturbations, B. Am. Meteorol. Soc., 74, 2317-2330, 1993.

Toth, Z. and Kalnay, E.: Ensemble forecasting at NCEP: the breeding method. Mon. Weather Rev., 125, 3297-3318, 1997.

Vukicevic, T. and Errico, R. M.: The influence of artificial and physical factors upon predictability estimates using a complex limited-area model, Mon. Weather Rev., 118, 1460-1482, 1990.

Wandishin, M. S., Mullen, S. L., Stensrud, D. J., and Brooks, H. E.: Evaluation of a short-range multi-model ensemble system, Mon. Weather Rev., 129, 729-747, 2001.

Wellens, A., Moussiopoulos, N., and Sahm, P.: Comparisons of a diagnostic model and MEMO progrognostic model to calculate wind fields in Mexico City. In: Second International Conference on Air Pollution, Computational Mechanics Publ., Barcelona, Spain, 27-28, 1994.

Williams, M. D., Brown, M. J., Cruz, X., Sosa, G., and Streit, G.: Development and testing of meteorology and air dispersion models for Mexico City, Atmos. Environ., 29, 2929-2960, 1995.

Zhang, F., Bei, N. Nielsen-Gammon, J. W., Li, G., Zhang, R., Stuart, A. L., and Aksoy, A.: Impacts of meteorological uncertainties on ozone pollution predictability estimated through meteorological and photochemical ensemble forecasts, J. Geophys. Res., 112, D04304, doi:10.1029/2006JD007429, 2007a. 
Zhang, F., Bei, N., Rotunno, R., Snyder, C., and Epifanio, C. C.: Mesoscale predictability of moist baroclinic waves. J. Atmos. Sci., 64, 3579-3594, 2007b.

Zhang, F., Snyder, C., and Rotunno, R.: Mesoscale predictability of the 'surprise' 24-25 January 2000 snowstorm, Mon. Weather Rev., 130, 1617-1632, 2002.
Zhang, F., Snyder, C., and Rotunno, R.: Effects of moist convection on mesoscale predictability, J. Atmos. Sci., 60, 1173-1185, 2003.

Zhang, F., Odins, A. M., and Nielsen-Gammon, J. W.: Mesoscale predictability of an extreme warm-season precipitation event, Weather Forecast., 21, 149-166, 2006. 